\title{
Adherence to Diabetes Self-Management and the Associated Factors among Type 1 Diabetic Adolescents Attending Outpatient Diabetic Clinic at Public Hospitals in Addis Ababa, Ethiopia, 2021
}

Yomilan Geneti ( $\nabla$ ilaamee16@gmail.com )

Dire Dawa University

Kalkidan Wondwossen

Addis Ababa University

Mekonen Adimasu

Addis Ababa University

Dereje Deressa

Addis Ababa University

Fekadu Aga

Addis Ababa University

Magarsa Lami

Haramaya University

Lemesa Abdisa

Haramaya University

Seboka Abebe Sori

Wolkite University

Hirut Dinku

Wolkite University

\section{Research Article}

Keywords: Adherence, Diabetes, Self-management, Adolescents, ADSM

Posted Date: November 30th, 2021

DOI: https://doi.org/10.21203/rs.3.rs-1092496/v1

License: (c) (1) This work is licensed under a Creative Commons Attribution 4.0 International License.

Read Full License 


\section{Abstract \\ Objectives}

The purpose of this study was to determine the level of adherence to diabetes self-management and associated factors among type 1 diabetic adolescents attending outpatient diabetic clinics at Public Hospitals in Addis Ababa, Ethiopia.

\section{Methods}

An institutional-based cross-sectional study was carried out among 422 adolescents with type 1 diabetes attending outpatient diabetic clinics at four randomly selected public hospitals in Addis Ababa. The adolescents were interviewed using pretested questionnaires to give information on socio-demographic characteristics, medical factors, knowledge about type 1 diabetes, adherence to diabetes selfmanagement, self-efficacy, and social support related to type 1 diabetes. A variable that has a P-value of $<0.2$ in bi-variable logistic regression analysis was subjected to multivariable logistic regression analysis to control the confounding factors. The level of significance was pronounced at P-value $<0.05$.

\section{Results}

In this study, a total of 414 diabetic adolescents were interviewed making a $98.1 \%$ response rate. About 218 participants $(52.7 \%)$ had poor adherence to overall diabetes self-management. Self-efficacy (AOR=8.7, 95\% Cl:1.9-14.1, $P=0.005)$, social support ( $A O R=4.6,95 \% \mathrm{Cl}: 1.5-13.5, P=0.006)$, age (AOR=0.2, $95 \% \mathrm{Cl}: 0.1-0.4, \mathrm{P}=0.001)$, good knowledge of the disease (AOR=9.046, 95\% Cl:3.83-13.5, $\mathrm{P}=0.000$ ), moderate knowledge (AOR=6.763,95\% Cl:2.18-12.921, $\mathrm{P}=0.001)$, and time since diagnosis of type 1 diabetes $(A O R=0.1,95 \% \mathrm{Cl}: 0.02-0.2, P=0.005)$ were significantly associated with adherence to diabetes self-management.

\section{Conclusions and Recommendations:}

More than half of this population had poor adherence. The finding suggested that implementing a comprehensive guideline of adherence and expanding the recurrence of follow-up visits could be important for this population.

\section{Introduction}

Adherence to diabetes self-management of adolescents with type 1 diabetes in the process of learning to interact with the complex nature of the disease. It is a daily, dynamic, active, and proactive process that involves collaboration with the health care providers. It is the interactions of the health-related behaviors for the chronic conditions of the disease (1). 
Control of type 1 diabetes (T1D) mandates adolescents' adherence to overall diabetes treatment guidelines. Adolescents should get socially touchy and formatively suitable diabetes self-management instruction. Motivated adolescents who are dynamic in their self-management are exceptionally critical for viable control of the disease(2).

Nowadays, research shows that the cause for destitute adherence to diabetes self-management of adolescents with T1D is various. These factors are shorter time since diagnosis of the disease, Presence of comorbidities, depressive symptoms, poor patient-provider relationships, less frequency of visits to the diabetic clinics, and the like(3).

Indeed, in the event that most inquiries have centered on adherence to medicine, adherence moreover includes other health-related behaviors that expand past taking endorsed drugs. Few studies are conducted to assess the overall adherence to diabetes self-management domains in adolescents(4-6).

Thus, adherence to diabetes self-management (ADSM) has five main domains. These main domains are adherence to insulin administration, dietary management, management of hypoglycemia, blood glucose testing, and regulation of exercise(7).

The prevalence of poor ADSM among adolescents with T1D is very high worldwide. Especially, it is higher in middle and low-income countries than in high-income countries $(8,9)$. In high-income countries (America for example) poor adherence is $20 \%(10)$. Whereas, the population in low- and middle-income countries is especially being affected by easily modifiable factors. For instance, a study showed that $66 \%$, $89 \%, 79 \%$, and $21 \%$ of adolescents with T1D in Palestine are non-adherent to glucose testing, dietary management, exercise, and insulin administration respectively (8).-

In Uganda, the overall prevalence of poor ADSM among adolescents is $63 \%$. Similarly, poor adherence to insulin administration, glucose testing, and dietary management were $48 \%, 23.5 \%$, and $70.5 \%$ respectively(5). Similarly, in Cameroon, the mean poor ADSM of adolescents was $67 \%(11)$.

Poor ADSM may impose different impacts on the health care system of adolescents. Hence, most adolescents complain of diabetes ketoacidosis (DKA), anorexia nervosa, micro and macrovascular disease $(12,13)$. Similarly, a study showed that adolescents with poor ADSM have a poor quality of life. They are especially at high risk for psychiatric disorders and anxiety symptoms(14). Moreover, adolescents with poor ADSM have prolonged hospital admissions, higher levels of depression, and poor self-efficacy(15).

Some of the factors associated with ADSM were: socio-demographic characteristics, time since diagnosis of the disease, self-efficacy, social support, knowledge about the disease, and comorbidities(3, 16).

Moreover, the ADSM plan and its domains are very difficult in adolescents. In many countries, especially in economically disadvantaged families, access to insulin and self-management tools is scarce. This may lead to severe disability and early death as a result of ketones building up in the body(17). 
Thus, proper ADSM by developing a trusting and motivating relationship between health care professionals and adolescents with T1D is the only option to improve health status(18).

Though the issue of ADSM requires strong devotion and considerable attention, few studies were conducted to show the gap and magnitude of the problem. To the extent of the investigator's knowledge, there has been no published study that determines ADSM and associated factors among adolescents with T1D in Ethiopia. Therefore, the study aimed to assess ADSM of adolescents with T1D and associated factors in the study area. Hence, such types of data would show the level of poor adherence and would be essential for the care delivery services of the adolescents to fill the gaps to resolve the problem.

\section{Methods And Materials}

\section{Study Area and Period}

The study was conducted in Addis Ababa city, Ethiopia, from March 10 to April 25, 2021. Addis Ababa city was conveniently selected as a study area based on the goals of the study, feasibility, and the availability of diabetic clinics at all levels of the public health care system in the study area.

\section{Study Design}

An institutional-based descriptive cross-sectional study design was used.

\section{Source Population and Study Population}

All adolescents with T1D who visited the outpatient department at public hospitals in Addis Ababa were the source populations.

\section{Inclusion and Exclusion Criteria}

All adolescents with T1D who visited the outpatient department at selected public hospitals in Addis Ababa and those on insulin treatment at least for 1 year period before commencement of the study were included in the study. Adolescents who were unable to speak, those who had a major hearing problem, those who have serious physical and mental retardation were excluded from the study.

\section{Sample Size Determination}

The sample size was determined by using single population proportion formula. Using standard normal value corresponding to a $95 \%$ confidence interval $(\mathrm{Cl})$, taking a margin of error as $5 \%$ and Prevalence $(\mathrm{P})$ 
of $50 \%$ (prevalence of ADSM of T1D for adolescents in Ethiopia was not known). Then by taking a $10 \%$ non-response rate the final sample size was 422.

\section{Sampling Techniques}

From the ten public hospitals in Addis Ababa city that give chronic follow-up care services for adolescents with T1D, four public hospitals were selected by using a simple random sampling technique. The number of study units for each hospital was proportionally allocated based on the number of adolescents coming per month and those who were part of the final sample size were selected using systematic random sampling.

The number of adolescents coming per month were 340, 160, 320, \& 60 for Black lion Specialized Hospital, Zewuditu Memorial Hospital, Yekatit 12 Medical College Hospital \& Menilik II Referral Hospital respectively. Then by using the proportional allocation formula the number of study units of Black lion Specialized Hospital, Zewuditu Memorial Hospital, Yekatit 12 Medical College Hospital, and Menilik II Referral Hospital was 163, 76, 154, and 29 respectively.

\section{Operational Definitions}

Adolescents: Are the population of human beings is conventionally understood as the years between 10 \& 18 years old (19).

Adherence: This is the extent to which a person's behavior corresponds with the advice from health care providers (1).

Adherence to Diabetes Self-management: Refers to behaviors such as following adherence to the management of insulin administration, dietary management, management of hypoglycemia, blood glucose testing, and regulation of exercise. The percentage was calculated and categorized as good adherence to diabetes self-management if 'diabetes self-management profile self-report questionnaire' scores $>50 \%$ and poor adherence to diabetes self-management for scores $<50 \%(7,20)$.

\section{Study Variables}

Dependent Variables: adherence to diabetes self-management (ADSM)

Independent Variables: Socio-demographic Factors, Personal Factors, Behavioral Factors, and Social Factors.

\section{Data Collection Method}

\section{Data Collection Instrument}


A structured and pretested questionnaire was prepared and an interview technique was used for data collection. All of the questions were prepared in English and translated to Amharic by experts and backtranslated to English for consistency.

\section{Data Collectors}

Four trained BSc nurse professionals and two BSc nurse professionals were assigned as data collectors and supervisors respectively. Two days of training was given on the overall objective of the study, questionnaire clarification, sampling strategy, ethical considerations, how to facilitate and supervise the data collection process.

\section{Data Collection Procedures}

Face-to-face interview using a structured questionnaire was used for the data collection. A consent form, assent form, and an information sheet with details of the study were given to the participants and their families to obtain informed consent. Participants were assured of their confidentiality through anonymity by using code numbers on their questionnaires.

Subsequently, those who are willing to participate in the study were asked the questionnaire after taking informed, voluntary, and signed consent and assent. Data collectors guided and facilitated the data collection process by giving directions, clarifications, and checking for completeness of the data. Supervisors and the principal investigator also have followed the overall activities daily.

\section{Data Quality Assurance}

The quality of data was assured by properly designing the tool, and the questionnaires were pretested in St. Paul Generalized Specialized Hospital and Tirunesh Beijing Hospital using 5\% of the sample size, on 21 study units. The questionnaire was translated to Amharic language and back-translated into English by another person to check for consistency and similarity.

The data collection tool was assessed for completeness, consistency, applicability, and important modifications were made before the actual data collection. The study procedures protected the patient's privacy by allowing anonymous and voluntary participation. A frequency check was done for controlling errors during data analysis and the Cronbach alpha reliability test was calculated using SPSS and it was 0.72 .

\section{Data Processing and Analysis}

The data was collected by using Kobo collect software version 1.30 .1 from randomly selected adolescents with T1D who fulfilled the inclusion criteria and those who visited outpatient departments during the study period at selected public hospitals. Then the data was checked and cleaned in excel 
software for exporting to SPSS version 25 software for analysis. Incomplete and inconsistent data were excluded from the analysis. The results of the descriptive statistics were expressed as percentages and frequencies.

Associations between independent and dependent variables were analyzed first using bivariable analysis to identify factors that were associated with the outcome variable. Those variables which were found to have an association with the outcome variable at $\mathrm{P}<0.2$ and which fitted for binary logistic regression model were entered to multivariable logistic regression analysis to control the confounding factors. Then the fitness of the model was checked using Hosmer and Lemeshow goodness of fit. The magnitude of the association between the different variables in relation to dependent was measured using an adjusted odds ratio $(\mathrm{AOR})$ and $95 \% \mathrm{Cl}$ and $\mathrm{P}<0.05$ were considered to be statistically significant.

\section{Results}

\section{Sociodemographic Characteristics of Adolescents with Type 1 Diabetes}

A total of 422 diabetic adolescents were selected to participate in this study, among these, 414 participated making a $98.1 \%$ response rate. The data was collected from Black lion Specialized Hospital, Yekatit 12 Medical College Hospital, Zewditu Memorial Hospital, and Menilik II Referral Hospital. The majority of the participants $234(56.5 \%)$ were female. The age of the respondents ranged from 10 to 18 years with a mean age of 13.64 years. About $211(51 \%)$ were found within the age group of 15 to 18 years. Of the total respondents, about $262(63.3 \%)$ had primary level (1-8 grade) of education (Table 1).

Table 1

Distribution of socio-demographic characteristics of adolescents with type 1 diabetes in selected public hospitals in Addis Ababa, March to April 2021 ( $n=414)$.

\begin{tabular}{|llll|}
\hline Characteristics & Categories & Frequency(n=414) & Percent (\%) \\
\hline Age & 10 to 14 years & 203 & 49.0 \\
Category & 15 to 18 years & 211 & 51.0 \\
Sex & Male & 180 & 43.5 \\
\cline { 2 - 4 } & Female & 234 & 56.5 \\
\hline Educational status & Unable to read and write & 42 & 10.1 \\
\cline { 2 - 4 } & Primary level (1-8 grade) & 262 & 63.3 \\
\cline { 2 - 4 } & Secondary level (9-12 grade) & 101 & 24.4 \\
\hline
\end{tabular}

\section{Medical Characteristics of Adolescents with Type 1} Diabetes 
Out of the total 414 respondents, $227(54.8 \%)$ of the total participants were diabetic for at least 6 years and $247(59.7 \%)$ of the total participants were receiving insulin injections for a duration of at most 5years. All of the participants were on insulin injection with the mean duration of receiving insulin medication 4.86 years. The mean time since diagnosis with the disease was 5.7 years and $79.7 \%$ of the total participants were diagnosed with diabetes after the age of 6 . The majority of the participants (99\%) had no comorbidities and Hypertension was found to be the only comorbidity that was reported in this study (Table 2).

Table 2

Distribution of Medical characteristics of Adolescents with T1D in selected public hospitals in Addis Ababa, March to April 2021 ( $\mathrm{n}=414)$.

\begin{tabular}{|llll|}
\hline Characteristics & Categories & Frequency(n=414) & Percentage (\%) \\
\hline Time since diagnosis of T1D & 1 to 5 years & 187 & 45.2 \\
\cline { 2 - 4 } & 6years and above & 227 & 54.8 \\
\hline Age at diagnosis with T1D & 1 to 5 years & 84 & 20.3 \\
\cline { 2 - 4 } & 6 years and above & 330 & 79.7 \\
\hline Duration of taking insulin medications & 1 to 5 years & 247 & 59.7 \\
\cline { 2 - 4 } & 6 years and above & 167 & 40.3 \\
\hline Comorbidities & Yes & 2 & .5 \\
\cline { 2 - 4 } & No & 412 & 99.5 \\
\cline { 2 - 4 } & & &
\end{tabular}

\section{Level of Adherence to Diabetes Self-Management}

The overall prevalence of good adherence to diabetes self-management for the participants was $47.3 \%$ (196 participants) and the prevalence of total poor adherence to diabetes self-management was $52.7 \%$ (218 participants) Cl:95\% $(0.47,0.57)$ (Figure 1).

One hundred forty-three participants $(29 \%)$ were sometimes given their insulin injection more than 30 minutes late and the majority of them sometimes took less insulin than usual. The majority of respondents (40\%) rarely estimate their food to figure out how much to eat since being diagnosed with diabetes and $35 \%$ of the total participants never consumed fast foods. Sometimes, $37.4 \%$ of respondents had changed insulin dose, diet, or exercise when their blood glucose ran high and $22 \%$ of them did a ketone test when they were sick (Table 3). 
Table 3

Adherence to diabetes self-management of adolescents with T1D in Addis Ababa Public hospitals, March to April $2021(n=414)$.

\begin{tabular}{|c|c|c|c|c|c|}
\hline Questions & Never & $\begin{array}{l}\text { Almost } \\
\text { Never }\end{array}$ & Sometimes & $\begin{array}{l}\text { Almost } \\
\text { Always }\end{array}$ & Always \\
\hline $\begin{array}{l}\text { How often have you } \\
\text { received an insulin } \\
\text { injection more than thirty } \\
\text { minutes later? }\end{array}$ & 71(17.1\%) & $48(11.6 \%)$ & $121(29.2 \%)$ & $65(15.7 \%)$ & $109(26.3 \%)$ \\
\hline $\begin{array}{l}\text { How often have you } \\
\text { received less insulin than } \\
\text { you should have? }\end{array}$ & $68(16.4 \%)$ & $28(6.8 \%)$ & $225(54.3 \%)$ & $44(10.6 \%)$ & $49(11.8 \%)$ \\
\hline $\begin{array}{l}\text { How often have you } \\
\text { received more than you } \\
\text { should have? }\end{array}$ & $122(29.7 \%)$ & $55(13.3 \%)$ & $123(29.5 \%)$ & $70(16.9 \%)$ & $44(10.6 \%)$ \\
\hline $\begin{array}{l}\text { How often have you } \\
\text { missed insulin when you } \\
\text { forgot or were too busy? }\end{array}$ & $105(25.4 \%)$ & 72(17.4\%) & 137(33.1\%) & $44(10.6 \%)$ & $56(13.5 \%)$ \\
\hline $\begin{array}{l}\text { Did you usually } \\
\text { approximate your meal to } \\
\text { forecast how much to eat? }\end{array}$ & 45 (10.9\%) & $167(40.3 \%)$ & $90(21.7 \%)$ & 79(19.1\%) & $33(8.0 \%)$ \\
\hline $\begin{array}{l}\text { How often have you } \\
\text { consumed fast food such } \\
\text { as sweets, cookies, cakes } \\
\text { ice cream, chips, or others? }\end{array}$ & 144(34.8\%) & $104(25.1 \%)$ & $63(15.2 \%)$ & 76(18.4\%) & $27(6.5 \%)$ \\
\hline $\begin{array}{l}\text { How often have you } \\
\text { consumed more than what } \\
\text { was on your meal plan? }\end{array}$ & 79 (19.1\%) & $40(9.7 \%)$ & $216(52.2 \%)$ & $51(12.3 \%)$ & $28(6.8 \%)$ \\
\hline $\begin{array}{l}\text { Before you ate more than } \\
\text { usual, did you make any } \\
\text { insulin changes? }\end{array}$ & $130(31.4 \%)$ & 72(17.4\%) & $99(23.9 \%)$ & $81(19.6 \%)$ & $32(7.7 \%)$ \\
\hline $\begin{array}{l}\text { Before you ate less than } \\
\text { usual, did you make any } \\
\text { insulin changes? }\end{array}$ & $99(23.9 \%)$ & $90(21.7 \%)$ & $114(27.5 \%)$ & $50(12.1 \%)$ & $61(14.7 \%)$ \\
\hline $\begin{array}{l}\text { In the past } 3 \text { months, how } \\
\text { often have you eaten less } \\
\text { than what was planned? }\end{array}$ & $67(16.2 \%)$ & $58(14.0 \%)$ & $185(44.7 \%)$ & $51(12.3 \%)$ & $53(12.8 \%)$ \\
\hline $\begin{array}{l}\text { Did you keep something } \\
\text { handy if your sugar got too } \\
\text { low? }\end{array}$ & $\begin{array}{l}52 \\
(12.6 \%)\end{array}$ & $\begin{array}{l}36 \\
(8.7 \%)\end{array}$ & $123(29.7 \%)$ & $73(17.6 \%)$ & $130(31.4 \%)$ \\
\hline $\begin{array}{l}\text { If you think you had low } \\
\text { blood sugar, how often did } \\
\text { you check it before treating } \\
\text { it? }\end{array}$ & $\begin{array}{l}68 \\
(16.4 \%)\end{array}$ & $\begin{array}{l}30 \\
(7.2 \%)\end{array}$ & $167(40.3 \%)$ & $64(15.5 \%)$ & $84(20.3 \%)$ \\
\hline
\end{tabular}




\begin{tabular}{|c|c|c|c|c|c|}
\hline Questions & Never & $\begin{array}{l}\text { Almost } \\
\text { Never }\end{array}$ & Sometimes & $\begin{array}{l}\text { Almost } \\
\text { Always }\end{array}$ & Always \\
\hline \multirow{2}{*}{$\begin{array}{l}\text { How often do you treat } \\
\text { your low blood sugars if it } \\
\text { happens? }\end{array}$} & 15 & 34 & \multirow[t]{2}{*}{$97(23.4 \%)$} & \multirow[t]{2}{*}{$128(30.9 \%)$} & \multirow[t]{2}{*}{$138(33.3 \%)$} \\
\hline & (3.6\%) & (8.2\%) & & & \\
\hline \multirow{2}{*}{$\begin{array}{l}\text { Did you hold diabetic } \\
\text { identification, like a card or } \\
\text { bracelet? }\end{array}$} & 332 & 34 & \multirow[t]{2}{*}{$32(8.8 \%)$} & \multirow[t]{2}{*}{$37(9.3 \%)$} & \multirow[t]{2}{*}{$19(4.7 \%)$} \\
\hline & $(80.2 \%)$ & (8.2\%) & & & \\
\hline $\begin{array}{l}\text { How often have you } \\
\text { checked your blood sugar? }\end{array}$ & $28(6.8 \%)$ & $32(7.7 \%)$ & 61(14.7\%) & $106(25.6 \%)$ & $187(45.2 \%)$ \\
\hline $\begin{array}{l}\text { How often did you do a } \\
\text { blood sugar check within } \\
30 \text { minutes before a meal? }\end{array}$ & $87(21.0 \%)$ & $117(28.3 \%)$ & $89(21.5 \%)$ & 77(18.6\%) & $44(10.6 \%)$ \\
\hline $\begin{array}{l}\text { How often did you do a } \\
\text { blood sugar check within } \\
2-3 \text { hours after heavy } \\
\text { exercise? }\end{array}$ & 73(17.6\%) & 138(33.3\%) & $111(26.8 \%)$ & 72(17.4\%) & $20(4.8 \%)$ \\
\hline $\begin{array}{l}\text { How often did you do a } \\
\text { blood sugar check within } \\
2-3 \text { hours after a meal? }\end{array}$ & $67(16.2 \%)$ & $156(37.7 \%)$ & $86(20.8 \%)$ & $80(19.3 \%)$ & $23(5.6 \%)$ \\
\hline $\begin{array}{l}\text { How often have you } \\
\text { changed insulin dose, diet, } \\
\text { or exercise when blood } \\
\text { sugars run high? }\end{array}$ & 49 (11.8\%) & $94(22.7 \%)$ & $155(37.4 \%)$ & 36 (8.7\%) & $80(19.3 \%)$ \\
\hline $\begin{array}{l}\text { In the past } 3 \text { months, if } \\
\text { you had two blood sugar } \\
\text { results above } 240 \text { in a row, } \\
\text { how often did you do a } \\
\text { ketone test? }\end{array}$ & $59(14.3 \%)$ & $132(31.9 \%)$ & $112(27.1 \%)$ & $65(15.7 \%)$ & $46(11.1 \%)$ \\
\hline $\begin{array}{l}\text { When you are sick, how } \\
\text { often do you do a ketone } \\
\text { test? }\end{array}$ & $164(19.6)$ & $91(\% 22.0)$ & $91(22.0 \%)$ & $67(16.2 \%)$ & $83(20.0 \%)$ \\
\hline $\begin{array}{l}\text { How often have you } \\
\text { engaged in exercise such } \\
\text { as running, or playing any } \\
\text { sports for at least twenty } \\
\text { minutes? }\end{array}$ & 71(17.1\%) & $48(11.6 \%)$ & $109(26.3 \%)$ & $65(15.7 \%)$ & $121(29.2 \%)$ \\
\hline $\begin{array}{l}\text { If you got more exercise } \\
\text { than usual, how often did } \\
\text { you change the meal plan } \\
\text { or insulin? }\end{array}$ & $39(9.4 \%)$ & $82(19.8 \%)$ & $94(22.7 \%)$ & 137(33.1\%) & $62(15.0 \%)$ \\
\hline $\begin{array}{l}\text { If you got less exercise } \\
\text { than usual, how often did } \\
\text { you change the meal plan } \\
\text { or insulin? }\end{array}$ & $90(21.7 \%)$ & $22(5.3 \%)$ & $117(28.3 \%)$ & $\begin{array}{l}120 \\
(29.0 \%)\end{array}$ & 65 (15.7\%) \\
\hline
\end{tabular}


Factors Associated with Adherence to Diabetes Self-Management.

Both bi-variable and multivariable logistic regression analyses were implemented to determine the factors that were associated with diabetes self-management. Ten variables were entered into bi-variable logistic regression. Then nine variables were transferred to multivariable logistic regression based on a $p$-value of $>0.2$. After controlling possible confounding effects of other covariates, Adolescents' knowledge about type 1 diabetes, age, time since diagnosis of the disease, self-efficacy, and social support were found to be significantly associated with adherence to overall diabetes self-management

Adolescents who had social support were 5times more adherent to overall diabetes self-management than those who had no social support ( $\mathrm{AOR}=4.6,95 \% \mathrm{Cl}$ : 1.5-13.5, $\mathrm{P}=0.006)$. Similarly, the participants with good self-efficacy were 9times more adherent to overall diabetes self-management than those who had poor self-efficacy (AOR=8.7, 95\% Cl: 1.9-14.1, $P=0.005)$.

Moreover, the adolescents with a shorter duration of time since diagnosis of T1D had 90\% more adherent to overall diabetes self-management than those who had a longer duration of time since diagnosis (AOR=0.1, 95\% Cl:0.02-0.2, $\mathrm{P}=0.001$ ). Likewise, participants with age below 14years were $86 \%$ more adherent to overall diabetes self-management than those with age above $15 y$ ears (AOR $=0.14,95 \% \mathrm{Cl}: 0.1$ $0.4, P=0.001)$.

Furthermore, the adolescents with good knowledge about type 1 diabetes were 9times more adherent to overall diabetes self-management than those with poor knowledge (AOR=9.046, 95\%Cl: 3.83-13.5, $\mathrm{P}=0.000$ ). Likewise, adolescents with moderate knowledge about type 1 diabetes were 8times more adherent to overall diabetes self-management than those with poor knowledge (AOR=6.763, 95\% $\mathrm{Cl}$ : 2.186-12.921, $\mathrm{P}=0.001)$. Whereas, the adolescent's educational status, level of education, duration of taking insulin, gender, and age of diagnosis were not associated with adherence to overall diabetes selfmanagement (Table 4). 
Table 4

Factors associated with overall diabetes self-management in multivariable analysis model among adolescents with type 1 diabetes in Addis Ababa Public health hospitals, March to April 2021( $n=414)$.

$\begin{array}{lllllll}\text { Variables } & \begin{array}{l}\text { Poor } \\ \text { adherence }\end{array} & \begin{array}{l}\text { Good } \\ \text { adherence }\end{array} & \begin{array}{l}\text { COR }(95 \% \\ \text { C.I) }\end{array} & \begin{array}{l}\text { P- } \\ \text { value }\end{array} & \begin{array}{l}\text { AOR }(95 \% \\ \text { C.I })\end{array} & \begin{array}{l}\text { P- } \\ \text { Value }\end{array}\end{array}$

\section{Educational level}

Unable to read and write

Primary level

171

91

$1.9(0.9$,

4.3)

Secondary level

12

89

$27(10.5$
$70.5)$

Tertiary level

2

7

$13(2.3$
$72.8)$

$0.004 \quad 10.5(2.6$

$0.093 \quad 1.1(0.2,5.7)$

0.901

$\begin{array}{ll}0.000 & \begin{array}{l}2.5(3.2, \\ 20.8)\end{array} \\ 0.004 & \begin{array}{l}10.5(2.6 \\ 43.5)\end{array} \\ & \end{array}$

0.002

\section{Gender}

Male

Female

56

124

1

1

72

0.2 (0.1,

$0.3)$

\section{Age of diagnosing}

1 to 5 years

39

45

1

1

6years and above

179

151

0.7 (0.5,

1.2)

$0.000 \quad 0.8(0.3,2.3) \quad 0.662$

\section{Duration of taking} insulin

\begin{tabular}{|c|c|c|c|c|c|c|}
\hline 1 to 5 years & 87 & 160 & 1 & & 1 & \\
\hline 6years and above & 131 & 36 & $\begin{array}{l}0.15(0.1 \\
0.23)\end{array}$ & 0.000 & $\begin{array}{l}0.9(0.1 \\
11.2)\end{array}$ & 0.960 \\
\hline
\end{tabular}

\section{Time since diagnosis}

of T1D

$\begin{array}{lllllll}1 \text { to } 5 \text { years } & 24 & 163 & 1 & 1 & \\ \text { 6years and above } & 194 & 33 & 0.03(0.02, & 0.000 & 0.1(0.02, & 0.001\end{array}$

\section{Participant's age}

10-14 years

60

143

1

1

*P-value is significant at $P<0.05$ P-value of Hosmer and Lemeshow Test $=0.18$ Note: $1=$ Reference 


\begin{tabular}{|c|c|c|c|c|c|c|}
\hline Variables & $\begin{array}{l}\text { Poor } \\
\text { adherence }\end{array}$ & $\begin{array}{l}\text { Good } \\
\text { adherence }\end{array}$ & $\begin{array}{l}\text { COR }(95 \% \\
\text { C.I) }\end{array}$ & $\begin{array}{l}\mathrm{P} \text { - } \\
\text { value }\end{array}$ & $\begin{array}{l}\text { AOR }(95 \% \\
\text { C.I) }\end{array}$ & $\begin{array}{l}\text { P- } \\
\text { Value }\end{array}$ \\
\hline $15-18$ years & 158 & 53 & $\begin{array}{l}0.14(0.09, \\
0.2)\end{array}$ & 0.000 & $0.2(0.1,0.4)^{*}$ & 0.001 \\
\hline \multicolumn{7}{|l|}{ Social Support } \\
\hline No & 131 & 24 & 1 & & 1 & \\
\hline Yes & 87 & 172 & $\begin{array}{l}10.8(6.5 \\
17.9)\end{array}$ & 0.000 & $\begin{array}{l}4.6(1.5 \\
13.5)^{\star}\end{array}$ & 0.006 \\
\hline \multicolumn{7}{|l|}{ Self-efficacy } \\
\hline Poor & 111 & 10 & 1 & & 1 & \\
\hline Good & 107 & 186 & $\begin{array}{l}19.3(9.7 \\
38.4)\end{array}$ & 0.000 & $\begin{array}{l}8.7(1.9 \\
14.1) *\end{array}$ & 0.005 \\
\hline \multicolumn{7}{|l|}{$\begin{array}{l}\text { Knowledge about } \\
\text { T1D }\end{array}$} \\
\hline Poor knowledge & 170 & 39 & 1 & & 1 & \\
\hline Moderate knowledge & 39 & 95 & $\begin{array}{l}9.5(5.7 \\
15.9)\end{array}$ & 0.030 & $\begin{array}{l}6.76(2.19 \\
12.92)^{\star}\end{array}$ & 0.001 \\
\hline Good knowledge & 9 & 62 & $\begin{array}{l}34.9(16 \\
75.7)\end{array}$ & 0.000 & $\begin{array}{l}9.05(3.83 \\
13.5) *\end{array}$ & 0.000 \\
\hline
\end{tabular}

\section{Discussion}

\section{Adherence to Diabetes Self-management}

Overall ADSM in adolescents with T1D is the process of developing understanding by learning to live with the complex nature of the disease in the social context. This study aimed to determine the level of ADSM and associated factors among adolescents with T1D in four diabetic clinics in Addis Ababa, Ethiopia.

Few studies had been performed to measure adherence to diabetes self-management, especially relating to the five domains of ADSM (adherence to insulin administration, dietary management, management of hypoglycemia, blood glucose testing, and exercise) in adolescents $(5,8,11,21)$.

This study reported overall ADSM among adolescents with T1D was poor in $52.7 \%$ of the participants. This level of poor ADSM was higher than what has been reported in Iraq (21). This difference in the level of adherence may be due to the difference in tools that were used in the study. However, when compared to what has been reported in Palestine and Cameroon $(8,11)$ the finding from this study was a better report. This discrepancy could be explained by methodological factors where there was a difference in study design, sample size, and tool that was used to collect data. 


\section{Factors Associated with Adherence to Diabetes Self- Management}

ADSM was significantly associated with age, time since diagnosis, knowledge about T1D, self-efficacy, and social support. The report from this study concluded that participants with age between 10 and 14 were $80 \%$ more adherent to diabetes self-management than those with age between 15 and 18 . This finding was consistent with the study conducted by Oxford University and Tanzania(22, 23). The reason why adherence decreases as age increases could be due to the fall in social support as the age of the participants increases.

Similarly, the adolescents with a shorter time since diagnosis of T1D had better adherence to diabetes self-management than adolescents with a longer time since diagnosis. This report was the same finding as to the studies from Tanzania and America $(22,24)$ but contradicted the study from Cameroon and Britain $(11,25)$. From this finding, we can conclude that as time since diagnosis increases the patients get bored with the diseases process which in turn decreases adherence.

Moreover, adolescents with good knowledge about T1D had 9times better ADSM than adolescents with poor knowledge. Likewise, adolescents with moderate knowledge about T1D were 7times better at ADSM than adolescents with poor knowledge. Previous studies also showed that greater adolescents' knowledge predicts better ADSM (26).

Furthermore, respondents who had good self-efficacy were 9times better at ADSM than patients who had poor self-efficacy, since they have higher self-esteem to control their disease. Several studies also reported that self-efficacy is the significant determinant factor for successful ADSM (27-29).

Finally, respondents who had social support (both family and friends support) manifest 5 times more adherent than those with no social support. The reason may be respondents who had good social support would share their concerns and burdens. Reports from different countries also found that lack of social support was significantly associated with low quality of life and poor $\operatorname{ADSM}(5,30)$.

Although studies from different parts of the world revealed that the presence of co-morbidities has a significant association with poor $\operatorname{ADSM}(31,32)$ the findings from this study do not indicate any association. Likewise, the finding from this study report showed that there was no significant association between ADSM and educational status. This report contradicts a study from Cameroon which revealed that adolescents with the educational status of tertiary level (College/University) were $30 \%$ more adherent than those who cannot read and write(11). Similarly, there was no significant association between the duration of taking insulin medication and ADSM.

Moreover, there is no significant relationship between the gender of the participants and the level of ADSM among adolescents with T1D; which was the same finding with a study conducted in Australia(33). Whereas this finding contradicted the report from Britain, which revealed that females showed 1.05 times good ADSM than males(25). 


\section{Strengths And Limitations}

\section{Strengths}

This study considered five domains of ADSM; adherence to the regulation of exercise, insulin administration, dietary management, blood glucose testing, and management of hypoglycemia, which were mostly studied separately in other studies. The study also included important influencing factors like adolescents' knowledge about T1D, self-efficacy, and social support. Furthermore, the data was collected by kobo collect software, which saves time and enhances the quality of the data. Finally, the findings of this study could be generalized to adolescents who were attending diabetes follow up at public health hospitals in Addis Ababa.

\section{Limitations}

This study didn't include diabetic adolescents who were attending follow up in private health facilities. Next, the data on diabetes self-management was also collected through self-reporting methods which may cause recall and social desirability biases. The cross-sectional nature of the data also made it impossible to reach the causal relationship between the different independent variables and ADSM. Finally, the absence of national guidelines on ADSM among adolescents, limits this study to focus on foreign countries' guidelines.

\section{Conclusions And Recommendations}

\section{Conclusions}

This study assessed ADSM and associated factors among adolescents with T1D. Around $52.7 \%$ of adolescents who participated in this study had poor ADSM. Knowledge about T1D, Age, Time since diagnosis of T1D, self-efficacy, and social support was significantly and positively associated with ADSM.

\section{Recommendations}

This study revealed that there was a need to improve ADSM for adolescents with T1D. We wish to recommend Addis Ababa health bureaus and health institutions management organize and provide continuous refreshing training on ADSM and related topics for health care providers to improve their knowledge on diabetes so that they can share their knowledge with adolescents with T1D. Setting advertisements on ADSM using mass media like television, radio, Facebook, and the like. We wish to recommend the ministry of health prepares a comprehensive guideline of ADSM.

The health care providers should provide age-specific education both separately and with the family of the adolescents on ADSM. The health care providers should prepare care plans that can increase adolescents' knowledge about ADSM. More than half of the adolescents were lower in educational status and almost all of them are in a transitional period from familial support to independent interaction 
to their disease condition. Thus, it is important to increase the frequency of follow-up visits in diabetic clinics to have good adherence and to minimize the complication of the disease. It is recommended to do further study by including private health institutions to increase the representativeness of the study with emphasis on the impact of interventions targeting those subgroups noted to be at higher risk of poor ADSM.

\section{Abbreviations}

ADSM: Adherence to diabetes self-management, AOR, Adjusted Odd Ratio; COR, Crude Odd Ratio, DKA, Diabetic Ketoacidosis; DKT, Diabetic Knowledge test; DSMP-SR, Diabetes Self-Management Profile Self report; T1D, Type 1 Diabetes

\section{Declarations}

\section{Availability of data}

All related data have been presented within the manuscript. The data set supporting the conclusion of this article is available from the corresponding author upon reasonable request.

\section{Acknowledgments}

Primarily, we would like to express our deepest gratitude to Addis Ababa University College of Health Sciences and Dire Dawa University for the logistic support of the study. Then, we would also like to extend our appreciation to public health facilities in Addis Ababa city for giving us the appropriate information. Finally, our heartfelt thanks go to data collectors, supervisors, study participants, and data clerks.

\section{Funding}

No funding

\section{Conflict of interests}

The authors declare that they have no conflict of interest.

\section{Authors' Contribution}

All authors participated in the conception and design, acquisition of data, or analysis and interpretations of data; took part in drafting the article, review the draft manuscript for intellectual content, and 
participated in the revision. All authors have read and approved the final version of the manuscript for publication. All authors agree to be accountable for all aspects of the work.

\section{References}

1. Modi AC, Pai AL, Hommel KA, Hood KK, Cortina S, Hilliard ME, et al. Pediatric self-management: a framework for research, practice, and policy. Pediatrics. 2012;129(2):e473-85.

2. Care D SS. 13. Children and Adolescents: Standards of Medical Care in Diabetes. Diabetes Care. 2019.

3. Riaz M, Basit A, Fawwad A, Ahmedani M, Rizvi Z. Factors associated with non-adherence to Insulin in patients with Type-1 diabetes. Pakistan journal of medical sciences. 2014;30:233-9.

4. Shrivastava SR, Shrivastava PS, Ramasamy J. Role of self-care in management of diabetes mellitus. Journal of diabetes and metabolic disorders. 2013;12(1):14.

5. Kyokunzire $\mathrm{C} M N$. Factors associated with adherence to diabetes care recommendations among children and adolescents with type 1 diabetes: a facility-based study in two urban diabetes clinics in Uganda [Corrigendum]. Diabetes Metab Syndr Obes. 2018;11:93.

6. Alkaiyat A, Hilo L, Braik T, Sayeh W, Alem I. Adherence to the management of type i diabetes among Palestinian patients in Nablus city: a cross-sectional study. adolescence.13:14.

7. Barola A, Tiwari P, Bhansali A, Grover S, Dayal D. Cross-cultural adaptation and psychometric evaluation of Hindi version of Diabetes Self-Management Profile-Self Report in Indian type 1 diabetes patients. Pediatric Diabetes. 2020.

8. Alkaiyat A, Hilo L, Braik T, Sayeh W, Alem I. Adherence to the management of type i diabetes among Palestinian patients in Nablus city: a cross-sectional study. adolescence. 2020;13:14.

9. Gandhi K, Vu B-MK, Eshtehardi SS, Wasserman RM, Hilliard ME. Adherence in adolescents with Type 1 diabetes: strategies and considerations for assessment in research and practice. Diabetes Management (London, England). 2015;5(6):485.

10. Daniels T, Goodacre L, Sutton C, Pollard K, Conway S, Peckham D. Accurate assessment of adherence: self-report and clinician report vs electronic monitoring of nebulizers. Chest. 2011;140(2):425-32.

11. Djonou C, Tankeu AT, Dehayem MY, Tcheutchoua DN, Mbanya JC, Sobngwi E. Glycemic control and correlates in a group of sub Saharan type 1 diabetes adolescents. BMC research notes. 2019;12(1):50.

12. Young V, Eiser C, Johnson B, Brierley S, Epton T, Elliott J, et al. Eating problems in adolescents with Type 1 diabetes: a systematic review with meta-analysis. Diabetic Medicine. 2013;30(2):189-98.

13. Gregory JM, Moore DJ, Simmons JH. Type 1 diabetes mellitus. Pediatrics in review. 2013;34(5):20315.

14. Herzer M, Hood KK. Anxiety symptoms in adolescents with type 1 diabetes: association with blood glucose monitoring and glycemic control. Journal of pediatric psychology. 2010;35(4):415-25. 
15. Abolfotouh MA, Kamal MM, El-Bourgy MD, Mohamed SG. Quality of life and glycemic control in adolescents with type 1 diabetes and the impact of an education intervention. International journal of general medicine. 2011;4:141.

16. Lloyd CE, Pambianco G, Orchard TJ. Does diabetes-related distress explain the presence of depressive symptoms and/or poor self-care in individuals with Type 1 diabetes? Diabetic medicine: a journal of the British Diabetic Association. 2010;27(2):234-7.

17. Federation ID. IDF Diabetes Atlas Ninth. Dunia: IDF. 2019.

18. Cameron FJ, Amin R, De Beaufort C, Codner E, Acerini CL. Diabetes in adolescence. Pediatric diabetes. 2014;15:245-56.

19. Curtis AC. Defining adolescence. Journal of adolescent and family health. 2015;7(2):2.

20. Toobert DJ, Hampson SE, Glasgow RE. The summary of diabetes self-care activities measure: results from 7 studies and a revised scale. Diabetes care. 2000;23(7):943-50.

21. Parecatty Sr T. Effectiveness of individual planned teaching on self-administration of insulin for patients with diabetes mellitus, receiving insulin in a selected hospital at mangalore 2015.

22. Noorani M, Ramaiya K, Manji K. Glycaemic control in type 1 diabetes mellitus among children and adolescents in a resource limited setting in Dar es Salaam-Tanzania. BMC endocrine disorders. 2016;16(1):1-8.

23. Lewin AB, Storch EA, Williams LB, Duke DC, Silverstein JH, Geffken GR. Brief report: normative data on a structured interview for diabetes adherence in childhood. Journal of pediatric psychology. 2010;35(2):177-82.

24. Chao A, Whittemore R, Minges KE, Murphy KM, Grey M. Self-management in early adolescence and differences by age at diagnosis and duration of type 1 diabetes. The Diabetes Educator. 2014;40(2):167-77.

25. Abubakari A-R, Cousins R, Thomas C, Sharma D, Naderali EK. Sociodemographic and clinical predictors of self-management among people with poorly controlled type 1 and type 2 diabetes: the role of illness perceptions and self-efficacy. Journal of diabetes research. 2016;2016.

26. Wysocki T, Lochrie A, Antal H, Buckloh LM. Youth and parent knowledge and communication about major complications of type 1 diabetes: associations with diabetes outcomes. Diabetes care. 2011;34(8):1701-5.

27. Krishna S, Boren SA. Diabetes self-management care via cell phone: a systematic review. Journal of diabetes science and technology. 2018;2(3):509-17.

28. Alvarado-Martel D, Ruiz Fernández $M$, Cuadrado Vigaray $M$, Carrillo A, Boronat $M$, Expósito Montesdeoca A, et al. Identification of psychological factors associated with adherence to self-care behaviors amongst patients with type 1 diabetes. Journal of diabetes research. 2019;2019.

29. Rezasefat Balesbaneh A, Mirhaghjou N, Jafsri AsI M, Kohmanaee S, Kazemnejad Leili E, Monfared A. Correlation between self-care and self-efficacy in adolescents with type 1 diabetes. Journal of Holistic Nursing And Midwifery. 2014;24(2):18-24. 
30. Joensen LE, Almdal TP, Willaing I. Type 1 diabetes and living without a partner: psychological and social aspects, self-management behaviour, and glycaemic control. Diabetes research and clinical practice. 2013;101(3):278-85.

31. Young E. Diabetes mellitus, associated co-morbidities and complications -A review. Journal of Medicine and Medical sciences. 2016;7:47-55.

32. Kong AP, Xu G, Brown N, So W-Y, Ma RC, Chan JC. Diabetes and its comorbidities-where East meets West. Nature Reviews Endocrinology. 2013;9(9):537.

33. Neylon OM, O'Connell MA, Skinner TC, Cameron FJ. Demographic and personal factors associated with metabolic control and self-care in youth with type 1 diabetes: a systematic review.

Diabetes/Metabolism Research and Reviews. 2013;29(4):257-72.

\section{Figures}

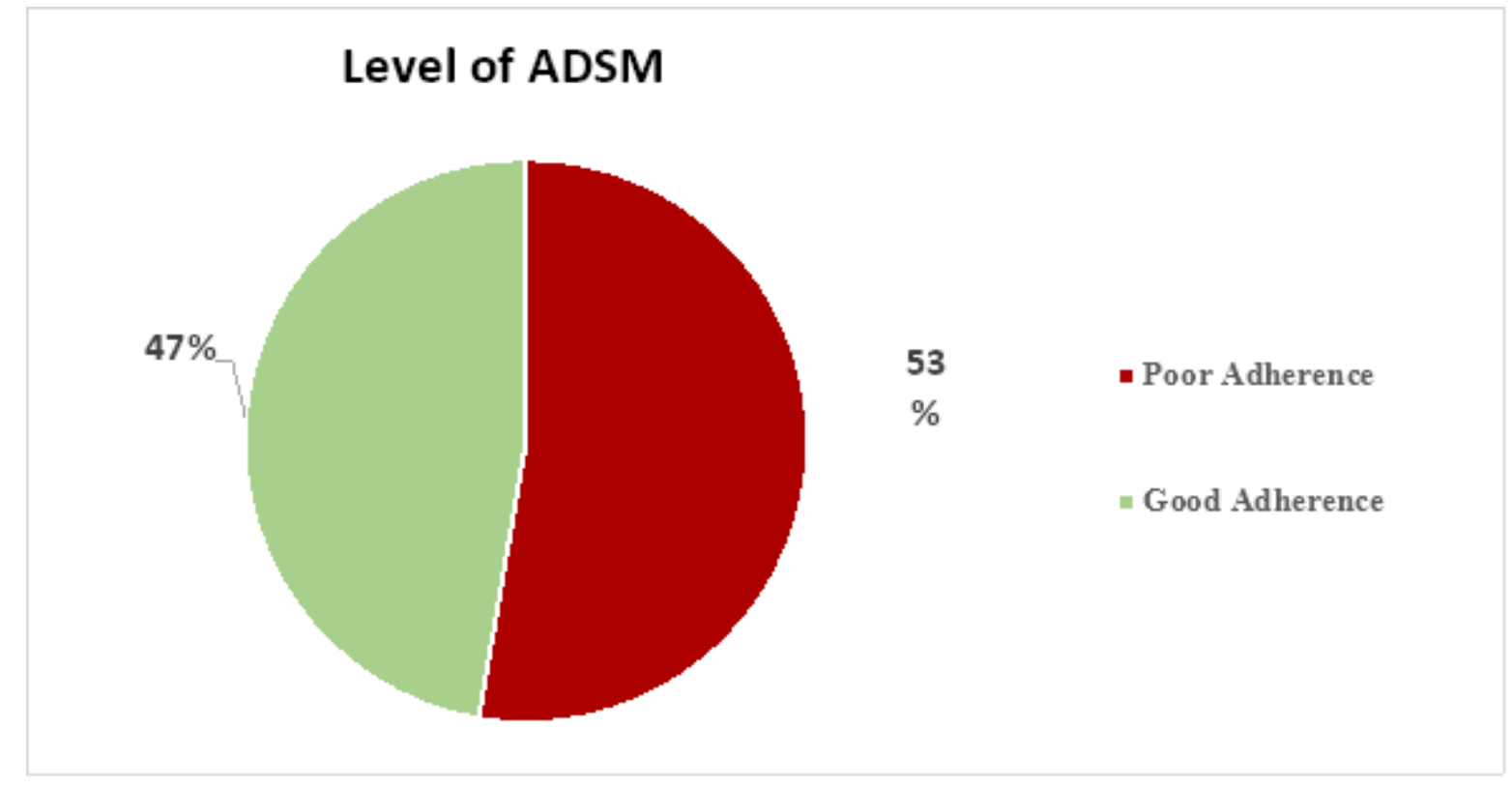

\section{Figure 1}

Level of ADSM of adolescents with T1D in Addis Ababa public health hospitals, March; to April 2021 $(n=414)$. 